\title{
Гранулометрический состав донных отложений залива Колесбухта (Западный Шпицберген)
}

\author{
Мещеряков Н.И. ${ }^{1}$, Духно Г.Н. ${ }^{1}$, Даувальтер В.А. ${ }^{2}$ Шарин В.В. ${ }^{3}$ \\ ${ }^{1}$ Мурманской морской биологический институт КНЦ РАН, Мурманск, meshcheriakov104@mail.ru \\ ${ }^{2}$ Институт проблем промышиленной экологии Севера КНЦ РАН, Апатиты, \\ vladimir.dauvalter@mail.ru \\ ${ }^{3}$ Санкт-Петербургский государственный университет, Полярная морская геологоразведочная экс- \\ педиция, Санкт-Петербург, sharin_v@mail.ru
}

Аннотация. Проведены научно-исследовательские работы в заливе Колесбухта (Западный Шпицберген). Отобраны пробы донных отложений различных участков залива. Мощность вскрытой толщи осадков составила от 7 до 13 см. Проведён гранулометрический анализ проб методом Батурина-Осборна. Рассмотрены особенности формирования осадков в заливе Колесбухта. Установлены факторы, определяющие условия осадконакопления в бассейне седиментации. Составлена карта-схема распределения донных отложений в заливе Колесбухта.

Ключевые слова: Гранулометрический состав, осадконакопление, литораль, Западный Шпицберген, залив Колесбухта, река Колес.

\section{Granulometric composition of bottom sediments of the Colesbukhta gulf (West Spitsbergen)}

\author{
Meshcheriakov N.I. ${ }^{1}$, Dukhno G.N. ${ }^{1}$, Dauvalter V.A. ${ }^{2}$, Sharin V.V. ${ }^{3}$ \\ ${ }^{1}$ Murmansk Marine Biological Institute KSC RAS, Murmansk, meshcheriakov104@mail.ru \\ ${ }^{2}$ Institute of the North Industrial Ecology Problems, Apatity \\ ${ }^{3}$ St. Petersburg Univesity, Polar Marine Geosurvery Expedition, St. Petersburg
}

\begin{abstract}
Scientific research has been conducted in the Gulf of Colesbukhta (West Spitsbergen). Samples of bottom sediments from different parts of the bay have been collected. Bottom sediments from different parts of the bay have been sampled. The thickness of the exposed sediment ranges from 7 to $13 \mathrm{~cm}$. The granulometric analysis of the samples has bcen carried out using the Baturin-Osborne method. The features of precipitation formation in the Colesbukta gulf are considered. The factors determining the conditions of sedimentation in the sedimentation basin are established. A map of the bottom sediments distribution in the Colesbukhta gulf has been compiled.

Key words: Granulometric composition, sedimentation, littoral, West Spitsbergen, Colesbukhta gulf, Coles river.

\section{Введение}

Изучение современного осадконакопления в высокоширотных заливах и фьордах является важной научной задачей, решение которой способно дополнить фундаментальные знания о особенностях протекания седиментогенеза в условиях изменения климата и дегляциации ледников в Арктике (Мавлюдов и др. 2012; Анциферова и др., 2014; Forland, Hanssen-Bauer, 2003; Forwick, Vorren, 2011). При изучении современного осадконакопления в подобных бассейнах седиментации особую роль следует отводить анализу гранулометрического состава донных отложений. Размерность частиц слагающих осадок, является важным показателем, который даёт возможность охарактеризовать условия осадконакопления в бассейне седиментации.

В результате развитой инфраструктуры, наиболее удобным полигоном для изучения осадконакопления являются заливы и фьорды острова Западный Шпицберген. Среди заливов и фьордов острова выделяется залив Колесбухта, он является относительно доступным и при этом наименее изученным в данном аспекте объектом.
\end{abstract}




\section{Район исследований}

Отбор проб выполнен в 2018 году в заливе Колесбухта (Западный Шпицберген) с борта НИС «Дальние Зеленцы», а также в ходе сухопутной экспедиции в район работ, при этом отобраны донные отложения различных участков залива (рис. 1).

Залив Колесбухта относится к системе залива Ис-фьорд и является одним из его многочисленных рукавов. Между заливами имеется свободный водо- и ледообмен. Залив Колесбухта простирается в юго-юго-восточном направлении при этом вдаётся в берег на 4.2 км, его ширина в устье по

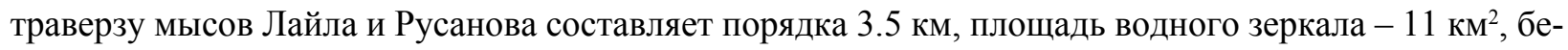
реговая линия - 13.5 км. Котловина залива имеет корытообразную форму, глубина увеличивается с юга на север. В большей части залива, глубина не превышает 50 м, однако на выходе в Ис-фьорд отмечаются глубины до 100 м.

Для залива характерна обширная литораль, так на западном побережье в период отлива осушается 400-500 м, максимально до 700 м в районе мыса Лайла, на восточном побережье - 170 м, в куту залива - 300 м. Крупнейшим водотоком водосбора является река Колес, впадающая в залив на юге.

\section{Материалы и методы}

Орудием отбора проб с борта НИС «Дальние Зеленцы» являлись дночерпатель Ван Вина и пластиковая колонка (d-55мм, h-150мм). Колонка донных отложений отбиралась из дночерпателя через верхние створки. Мощность вскрытой осадочной толщи составила от 7 до $13 \mathrm{cm.} \mathrm{При} \mathrm{об-}$ работке колонка отложений разделялась на слои мощностью 1 см, которые подвергались гранулометрическому анализу. На литорали проводились геоморфологические визуальные наблюдения в ходе пеших маршрутов, а также отбирались поверхностные донные отложения (рис. 1). Всего обработано 62 проб донных отложений депрессии и 6 проб донных отложений литорали залива.

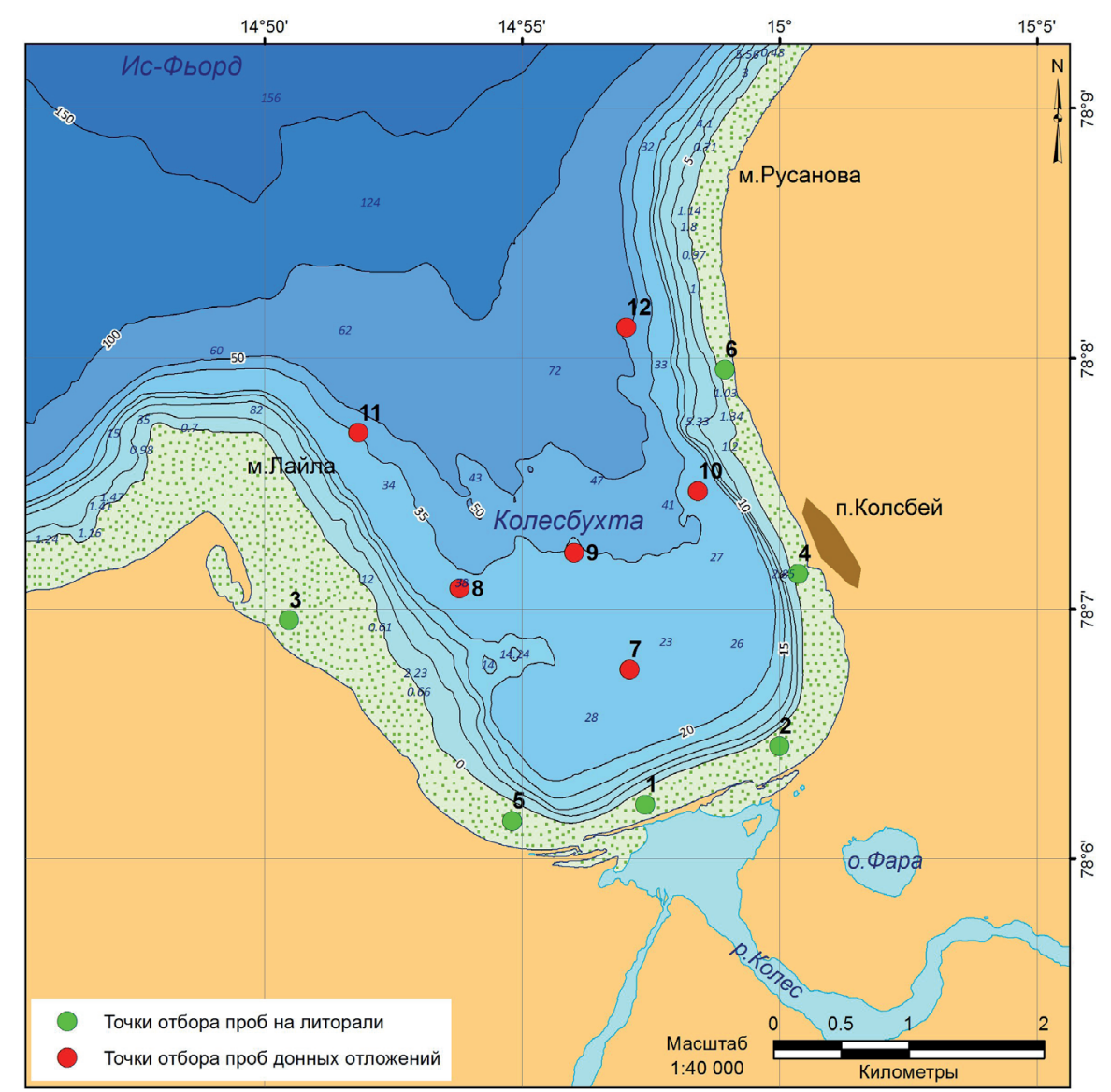

Рис. 1. Точки отбора проб в районе работ.

Fig. 1. Sampling points in the study area. 


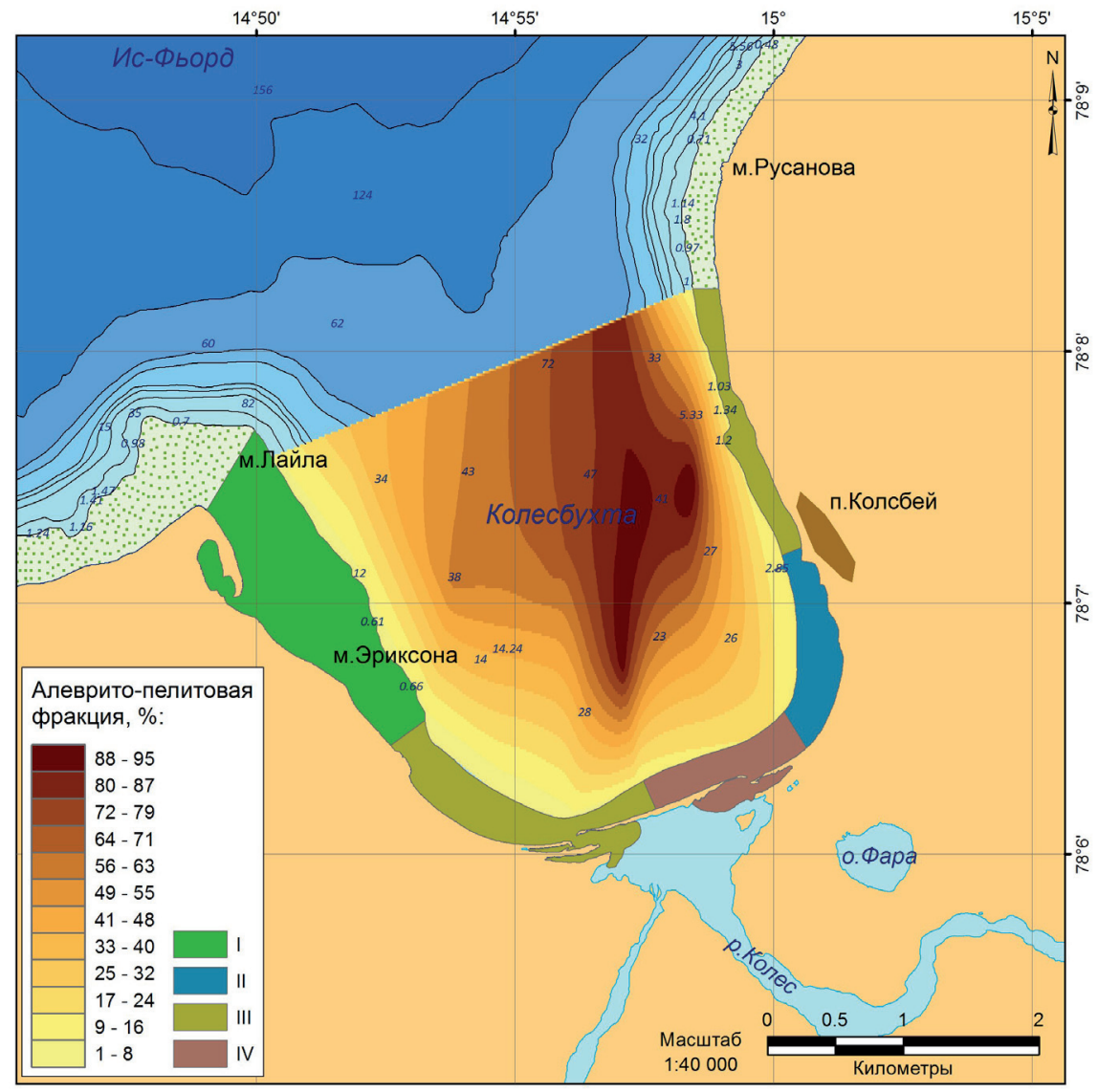

Рис. 2. Карта-схема распределения донных отложений залива Колесбухта.

I - разнозернистый песок, гравий, галька; II - мелкозернистый песок, алеврит, пелит; III - галька, гравий, крупнозернистый песок; IV - слабосортированный материал.

Fig. 2. Map of the distribution of bottom sediments of the Colesbukhta gulf.

I - inequigranular sand, gravel, pebbles; II - fine-grained sand, silt, pelite, III - pebbles, gravel, coarse sand; I $\mathrm{V}$ - poorly sorted material.

Гранулометрический анализ проб проводился в лаборатории ММБИ КНЦ РАН по методике Батурина-Осборна.

\section{Результаты исследования}

\section{Литораль}

На северо-западе залива, гранулометрический состав осадков, во много определяется обширной зоной осушки и мелководьем. Здесь сформировались осадки, сложенные разнозернистым песком с примесью гравийно-галечного материала в верхней части литорали. Южнее, где отмель сужается, распространены осадки, сложенные грубообломочным материалом, в основном галькой, гравием и крупнозернистым песком (рис. 2, табл.).

Гранулометрический состав донных отложений кута во многом определяется речным стоком реки Колес. Западная часть дельты реки Колес отделена от моря гравийно-галечным баром, простирающимся субширотно приблизительно на 1.3 км. Основной речной сток приходится на восточную часть кута. Следует отметить, что в западной части кута распространены осадки сложенные галечно-гравийным материалом с примесью крупнозернистого песка, в то время как осадки восточной части кута представлены слабосортированным материалом, включающим в себя от грубообломочных до мелкодисперсных частиц, с не значительным преобладанием разнозернистого песка (рис. 2, табл.). 
Таблица. Гранулометрический состав донных отложений литорали залива Колесбухта, в \%.

Table. The granulometric composition of the bottom sediments of the Colesbukhta gulf littoral, $\%$.

\begin{tabular}{|c|c|c|c|c|c|c|c|c|}
\hline $\begin{array}{c}\text { Точки } \\
\text { отбора }\end{array}$ & $>2$ & $2-1$ & $1-0.5$ & $0.5-0.25$ & $0.25-0.1$ & $0.1-0.05$ & $0.05-0.01$ & $<0.01$ \\
\hline 1 & 31.0 & 27.0 & 25.4 & 7.8 & 2.0 & 0.8 & 0.7 & 5.3 \\
\hline 2 & 21.7 & 13.0 & 11.3 & 7.3 & 16.8 & 13.5 & 9.3 & 7.1 \\
\hline 3 & 14.6 & 25.9 & 21.1 & 12.1 & 22.0 & 0.7 & 0.6 & 3.0 \\
\hline 4 & 0.8 & 0.5 & 0.4 & 0.4 & 59.7 & 19.5 & 5.7 & 9.3 \\
\hline 5 & 56.8 & 15.8 & 21.0 & 4.4 & 1.0 & 0.4 & 0.3 & 0.3 \\
\hline 6 & 54.9 & 36.2 & 4.5 & 1.1 & 0.9 & 0.9 & 0.5 & 1.0 \\
\hline
\end{tabular}

\section{Депрессия залива}

С увеличением глубины, доля мелкодисперсного материала в осадках увеличивается. Данная закономерность прослеживается повсеместно (рис. 2). Осадки представлены в основном мелкоалевритовыми и пелитовым материалом. Вдоль восточного борта отмечается наибольшее содержание пелитовой фракции в донных отложениях. Гранулометрический состав вскрытой толщи донных отложений депрессии залива имеет как несомненные сходства, так и различия. В основном преобладают мелкодисперсные осадки, однако локально прослеживаются включения зёрен грубообломочного материала (рис. 3).
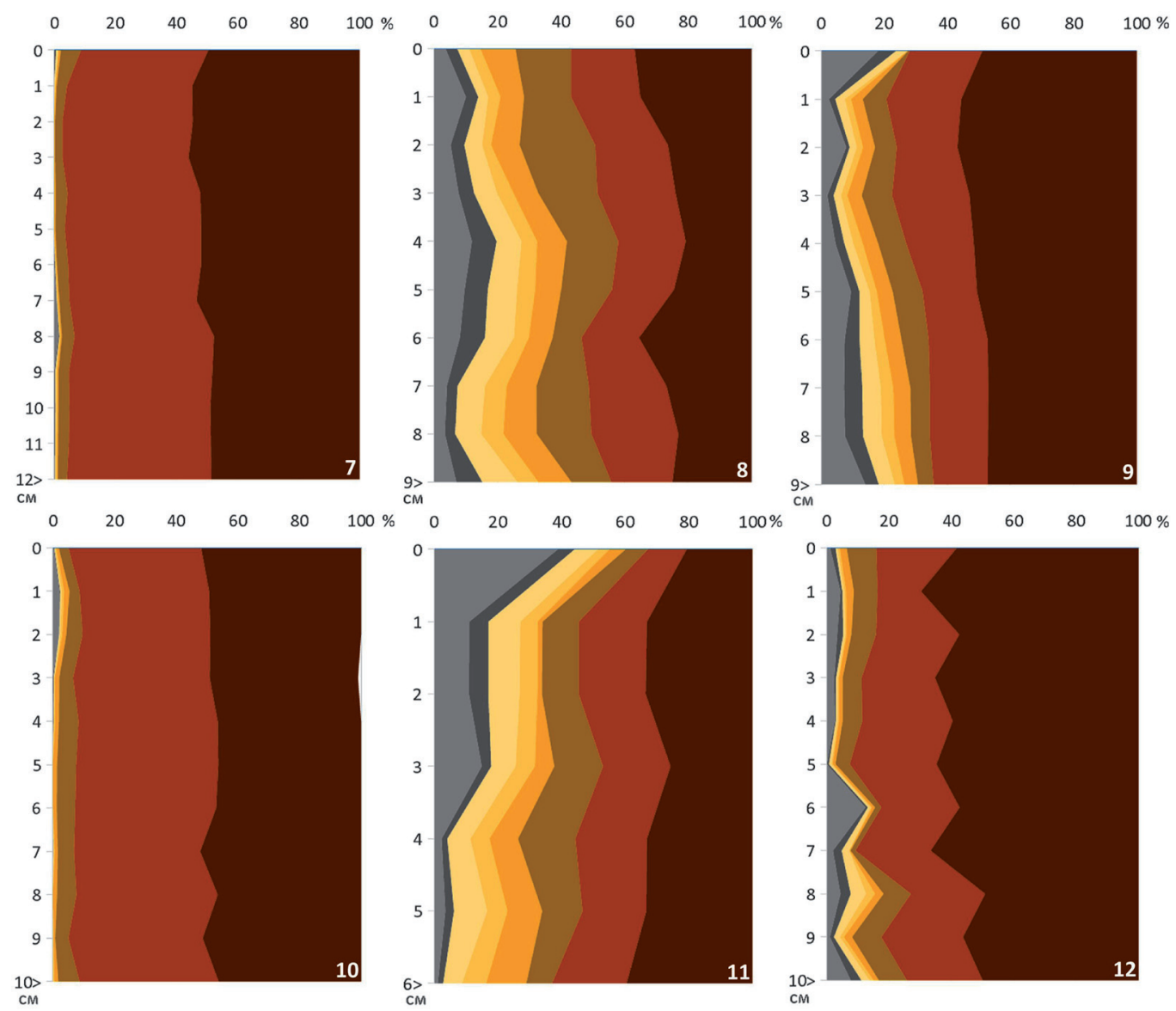

$\square>2 \square 2-1=1-0.5 \square 0.5-0.25 \square 0.25-0.1 \square 0.1-0.05 \square 0.05-0.01 \square<0.01$

Рис. 3. Гранулометрический состав вскрытой толщи донных отложений залива Колесбухта.

Fig. 3. The granulometric composition of the exposed sequence of bottom sediments of the Colesbukhta gulf. 


\section{Заключение}

Таким образом, гранулометрический состав донных отложений залива Колесбухта тесно связан с речным стоком, океанологическими процессами, а также геоморфологическими особенностями депрессии залива. Для литорали залива Колесбухта свойственно формирование разных типов осадков. Гранулометрический состав донных отложений литорали не однороден и варьирует в зависимости от локальных условий осадконакопления. В приглубых участках залива формируются осадки, сложенные мелкоалевритовым-пелитовым материалом, местами имеются включения зёрен более крупных фракций. Формирование пелитовых отложений отмечается вдоль восточного борта залива.

Данная работа является первым шагом по изучению седиментогенеза в заливе Колесбухта и нуждается в дополнительном проведении седиментологических исследований.

Авторы считают своим долгом поблагодарить заведующего лаборатории океанографии и радиоэкологии ММБИ КНЦ РАН, к.г.н., Ильина Г.В., за помощь и ценные советы по оформлению данной работы.

Работа выполнена в рамках темы госзадания «Комплексные исследования экосистем фьордов и морей, омывающих архипелаг Шпицберген».

\section{Литература}

1. Анциферова А.Р., Мокротоварова О.И., Сиеккинен Е.Д. Изменения климата на Архипелаге Шпицберген. Климатические особенности зимы 2013-2014 гг. // Комплексные исследования природы Шпицбергена Комплексные исследования природы Шпицбергена. М. Изд-во: ГЕОС. 2014. Вып. 12. С. 16-21.

2. Мавлюдов Б.Р., Саватюгин Л.М., Соловьянова И.Ю. Реакция ледников Земли Норденшельда (арх., Шпицберген) на изменение климата // Проблемы Арктики и Антарктики. 2012. Вып. 1 (91). С. 67-77.

3. Forland, E. J., Hanssen-Bauer, I. Past and future climate variations in the Norwegian Arctic: overview and novel analyses. Polar Res. 2003. V. 22. P. 113-124.

4. Forwick M, Vorren T.O. Stratigraphy and deglaciation of the Isfjorden area, Spitsbergen. Norwegian Journal of Geology. 2011. V. 90. P. 163-179. 